\title{
THE PROBLEM OF CHILDREN BORN IN LEPROSY COLONIES AND VILLAGES
}

\author{
by Sik LeONARd Rogkes.
}

1 am much indebted to Mr. William A. Lambert, of the Makete Leper Colony, an experienced.Toc $\mathrm{H}$ worker for BELRA, for the following data of family and children infections in leprosy villages in Tanganika Territory. They relate to leprosy villages founded by the Germans before the last great war, and deal firstly with the cases that have occurred in three generations of eighteen families. An analysis of these shows cases in one generation in five instances, in two generations in six and in all three generations in seven instances. The number of cases in a single generation varied from one to four, and the total cases in the eighteen families appears to be 82 , including both husband and wife in a number of instances. The disease was thus being maintained from one generation to another in many of these families. It should be mentioned that during the German occupation no treatment was supplied.

Of even greater interest are the data regarding the number and proportion of children who became infected from their parents. As there were some non-leper families with children in the same villages these serve as a control in the table below, which I have worked out from data supplied by Mr. Lambert.

Table of Number of Child Infections in Non-Leper and Lepler Families in the Makete Leper Colony

\begin{tabular}{llllrc} 
& \multicolumn{4}{c}{ Non-Lepers } & Lepers \\
Number of families $\ldots$ & $\ldots$ & $\ldots$ & $\ldots$ & 32 & 367 \\
Number of widows with children & $\ldots$ & $\ldots$ & 0 & 98 \\
Total families including the widows & $\ldots$ & $\ldots$ & 32 & 465 \\
Number of non-leper children in total families & 56 & 434 \\
Number of leper children in ditto & $\ldots$ & $\ldots$ & 0 & I5I \\
Total children in ditto .. $\ldots$ & $\ldots$ & $\ldots$ & $\ldots$ & 56 & 585 \\
Percentage of infected children $\ldots$ & $\ldots$ & $\ldots$ & 0 & $25.8 \%$
\end{tabular}

It appears from these data that one-fourth of the children in the leper families with one or both parents infected had contracted the disease. As there must be some too young to have yet done so, and others in the incubation period, or who may become infected by longer residence with their leprous parents, the total proportion of the children of leper parents who will contract the disease through prolonged residence is certain to be much more than one-fourth of the total thus exposed to infection. 
The above data once more illustrate the grave danger to children living with leper parents, now so generally recognized. They also appear to show that the children living in the same area with healthy parents escaped infection, but in view of their small numbers, and because it is not quite clear from the data supplied to me whether a few families with only child infections may be included among the infected class, it would not be safe to stress that point. Ample evidence, however, exists to prove that the earliest possible separation of the infants born to leper parents is absolutely necessary if a decrease in the incidence of leprosy is to be brought about. This indeed constitutes one of the gravest and most difficult problems in the control of leprosy by the voluntary isolation of the more infective cases in leper colonies and villages among backward races, so often living in one-roomed houses or huts in warm areas of Asia and Africa, and is worthy of further consideration.

\section{OTHER Data BEARing on the SUbJECT}

The great danger to children brought up by their leper parents was convincingly demonstrated during the earlier years of the great Culion Island leper settlement of the American sanitarians in the Philippines founded in Igo6. Some five thousand infected people lived under family conditions in their own houses and, as Lampe showed in Surinam, the fertility of leper women is not reduced, and that of males is only materially affected in advanced cases, several hundred children were born in the settlement. Later Denny recorded data to show that no less than 44 per cent of the children who had lived with their leper parents for from 7 to Io years had contracted the disease. Further figures up to 1922 showed that among 308 children born in the colony, and not separated from their parents, $\mathbf{1 4 . 2}$ showed clear infection and 18.8 showed suspicious symptoms, a total of 33 per cent. Others were doubtless infected and are still in the incubation stage. Again, in Manila Velesco reported on the examination of 80 out of 125 children born to 27 leper parents, an average of $4 \frac{1}{2}$ per family; he found $6 \mathrm{I}$, or 76.3 per cent to be suffering from leprosy, mostly in an early stage.

It is clear from such data that, in view of the large families of backward races mostly living in one roomed houses, and after allowing for the high infant mortality among them, such rates of child infection would not only suffice to maintain the incidence of leprosy indefinitely, but may well result in a steady increase in its prevalence. 
Preventive Measures. (1) Separation of Infants from BIRTH FROM LEPER PARENTS

It is generally admitted that leprosy is exceedingly rarely, if ever, hereditary, and even hereditary predisposition could not be proved by careful study of Philippine data. The effectiveness of removal of infants from their leper parents, and bringing them up in a separate part of the same institution, was demonstrated at Tarn Taran and other missionary controlled leper asylums in the latter part of the last century. Not only nearly all the children so removed, but their children also remained healthy. This plan has been adopted in recent years at Culion, and the results when available should prove of great interest. In the old prison-like compulsory isolation leper asylums the enforced separation of the sexes afforded another solution of the problem, which is also practicable in colonies in the more advanced countries such as South Africa.

In tropical countries the isolation of infants is greatly limited by the difficulties and cost of hand feeding of infants apart from their mothers, and in supplying the highly trained nurses essential for its success. In Madagascar the difficulty was met by placing the infants out with healthy wet nurses. In other places the infants are accommodated in a separate house from their parents, but taken to their mothers regularly to be suckled witi every precaution against infection. In Nigeria in some instances it has been found possible to send infants born in leper villages to be brought up by healthy relatives elsewhere; all admirable plans where practicable.

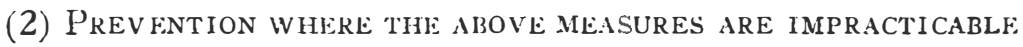

Among vast populations of Tropical Africa, China, Korea and parts of India any form of compulsory prophylaxis is impracticable; not only for the obvious lack of financial means, but even more by the wholesale hiding of the patients that would result, with the loss of opportunities for treatment in the more amenable early stages. Many thousands of infective cases are now flocking to the modern agricultural colonies and model leper villages in Africa and elsewhere, but the heads of families will as a rule refuse admission without their wives and also to part with their children from birth. Some other solution is therefore urgently required to prevent leprosy being maintained indefinitely through their progeny.

(3) Voluntary Sterilisation of the Leper Malf. Heads of Houskinol.ds

An effective solution of the dilemma has already been provided 
by Dr. R. M. Wilson, who built a model leper colony in Korea by leper labour. He has recorded that he found that the separation of the sexes and the prohibition of marriages in leper institutions resulted in many illegitimate children being born who are very liable to infection. Many suitable patients left, lived a married life in camps and had many children, half of whom contracted leprosy from their parents, thus perpetuating the disease. He therefore started a self-supporting colony by allowing couples to marry after the male partner had been sterilised by the simple operation of vasectomy under a local anaesthetic. This in no way interferes with normal married life, but suffices to prevent the procreation of children by the husband. The married couples built their own houses with a little help and so largely became self-supporting that their maintenance cost only one-fourth of the average. In $1936 \mathrm{Dr}$. Wilson was able to report the success of his bold experiment, which included permission for each couple to adopt one leper child from the colony; this helped towards solving another problem. At the end of three years the eleven families were well and happy. On the contrary, within a year to seventeen other couples, who had married without permission or sterilisation, nine children had been born and four of the mothers had relapsed under the strain of pregnancy and lactation. The husbands of this group now submitted to be sterilised and no more children have been born to them. The terrible, and expensive, tragedy reported in 1933 by Dr. Lampe from Dutch Guiana, of children born and infected in the leper asylum, who lived there for eighty years, can thus be averted.

Now that the practicability and success of Dr. Wilson's method have been demonstrated, there must surely be medical men in charge of leper colonies, who have gained the confidence of their patients to the degree necessary to enable them to follow his example: to the immense benefit of the present, and still more of future generations of leprosy-infected backward communities. From the time twenty years ago that I commenced a close study of half a century's medical literature bearing on the epidemiology of leprosy, I have urged the protection of children from infection as the most essential of prophylactic measures. The principles that BELRA has been working on for nearly that period of time have been proved to be sound by the results obtained on a limited scale in Africa and elsewhere, but the problem of the leper child remains the crux of the whole question. This note will not have been written in vain if it leads to the much wider adoption Dr. Wilson's solution of this remaining dilemma being dealt with. 